\section{Fundamentos e Prática em Hospital-dia e Reabilitação Psicossocial}

Sérgio Vieira Bettarello, Franscico Greco, Luis de Moraes Altenfelder Silva Filho, Maria Cecília Fernandes Silva. São Paulo: Atheneu; 2008. 267 p. ISBN 978-85-7379-969-9.

Neste livro, os autores descrevem sua experiência de mais de 10 anos à frente do Centro de Reabilitação e Hospital-dia (CRHD) do Instituto de Psiquiatria do Hospital das Clínicas da Faculdade de Medicina da Universidade de São Paulo, desde sua criação em 1996.

A obra está dividida em três partes: fundamentos, onde, ao longo de cinco capítulos, são apresentadas de forma concisa as premissas conceituais para o desenvolvimento do "Modelo Integrativo Dinâmico"; prática, com a descrição do dia-a-dia do funcionamento do serviço, seus grupos, oficinas etc.; e comentários finais, sobre o trabalho desenvolvido no CRHD.

O Modelo Integrativo Dinâmico é objeto do capítulo seis, e foi o termo cunhado pelos autores para sintetizar seus princípios de trabalho: ênfase na subjetividade, no contexto familiar e social; integração de novas experiências de viver no trabalho de reabilitação; e a importância da equipe inter e transprofissional.

Na segunda parte do livro (prática), após uma apresentação geral do serviço como um todo, o CRHD é detalhado em suas duas vertentes: Hospital-dia (capítulo 8), com a descrição das intervenções grupais, individuais e comentários sobre a interação entre as diferentes intervenções; e Centro de Reabilitação (capítulo 9), com suas oficinas (encadernação, culinária etc.), estágios oferecidos e suporte familiar e social. Outros aspectos importantes da organização do serviço, a triagem, o contrato com os pacientes e a alta do serviço, também são discutidos.

No Brasil, o modelo de hospital-dia (HD) vem sendo substituído na última década pelos Centros de Atenção Psicossocial (CAPS). Como discutido pelos autores, os dois modelos, HD e CAPS, não se sobrepõem, podendo-se atribuir ao HD duas valias diferentes: evitar ou encurtar as internações psiquiátricas, por possuir um ambiente mais continente à crise que os CAPS (o HD aqui estaria mais próximo das enfermarias de psiquiatria); e exercer ações em reabilitação psicossocial e proporcionar maior continência a casos ambulatoriais mais graves (estando por este lado mais próximo dos serviços ambulatoriais como o CAPS). Esta primeira atribuição, hoje muito pouco investida em nosso meio, tem muito de promissor: experiências piloto, como a do Hospital Geral do Pirajussara, na Grande São Paulo, têm desenvolvido unidades de HD dividindo espaço com unidades de internação em psiquiatria no hospital-geral, com excelentes resultados para os pacientes e otimização de recursos.

Mas é nos pontos de encontro entre HD e CAPS que este livro encontra sua maior importância: existe hoje uma grande carência de material de estudo para os milhares de profissionais de saúde mental trabalhando nos novos CAPS pelo país afora. Fundamentos e Prática em Hospital-dia e Reabilitação Psicossocial, quer pela clareza didática e embasamento bibliográfico apresentado, quer pelo rico conteúdo trazido pela experiência prática de um serviço de excelência, é um texto a ser recomendado a todos os profissionais da área.

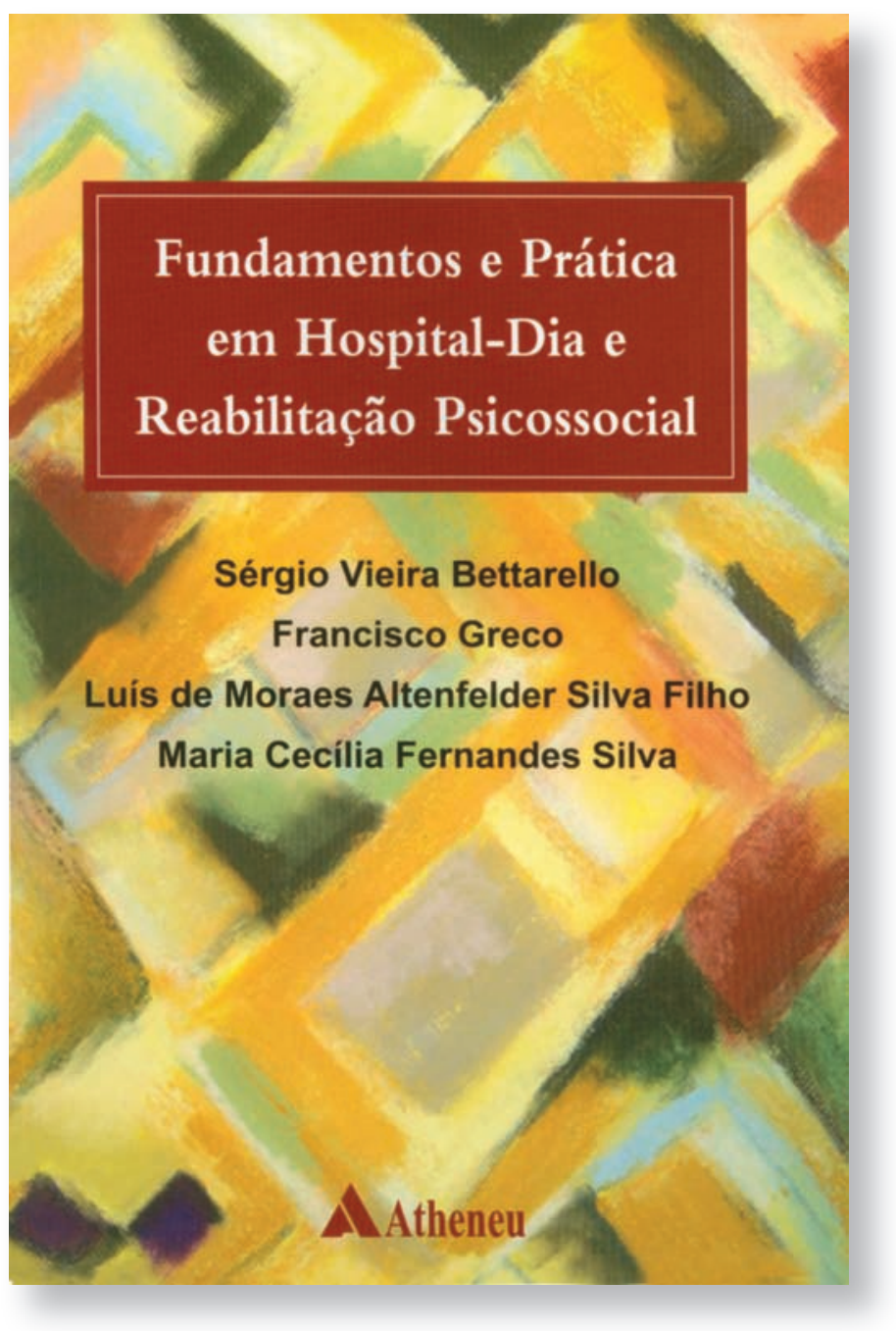

Justamente por esta vocação junto ao sistema público de atenção à saúde mental, sugerimos que se ampliem e revisem as informações relativas à política nacional de saúde e à legislação: por exemplo, a lei federal 10.216, de 6 de abril de 2001, que se originou do projeto do deputado Paulo Delgado, não dispõe sobre "a extinção progressiva dos manicômios e sua substituição por outros recursos assistenciais" (pag. 97), como estava em seu projeto original, mas sim "Dispõe sobre a proteção e os direitos das pessoas portadoras de transtornos mentais e redireciona o modelo assistencial em saúde mental".

Mario Dinis Mateus

Diretor técnico do convênio UNIFESP (Universidade Federal de São Paulo) e CAPS Prof. Luiz R. Cerqueira (Secretaria Estadual de Saúde de São Paulo) 